\title{
Relevance of the Fear-Avoidance Model for Chronic Disability after Traumatic Brain Injury
}

Citation for published version (APA):

Wijenberg, M., Hicks, A., Downing, M., Heugten, C., Stapert, S., \& Ponsford, J. (2020). Relevance of the Fear-Avoidance Model for Chronic Disability after Traumatic Brain Injury. Journal of Neurotrauma, 37(24), 2639-2646. https://doi.org/10.1089/neu.2020.7135

Document status and date:

Published: 15/12/2020

DOI:

10.1089/neu.2020.7135

Document Version:

Publisher's PDF, also known as Version of record

Document license:

Taverne

Please check the document version of this publication:

- A submitted manuscript is the version of the article upon submission and before peer-review. There can be important differences between the submitted version and the official published version of record.

People interested in the research are advised to contact the author for the final version of the publication, or visit the DOI to the publisher's website.

- The final author version and the galley proof are versions of the publication after peer review.

- The final published version features the final layout of the paper including the volume, issue and page numbers.

Link to publication

\footnotetext{
General rights rights.

- You may freely distribute the URL identifying the publication in the public portal. please follow below link for the End User Agreement:

www.umlib.nl/taverne-license

Take down policy

If you believe that this document breaches copyright please contact us at:

repository@maastrichtuniversity.nl

providing details and we will investigate your claim.
}

Copyright and moral rights for the publications made accessible in the public portal are retained by the authors and/or other copyright owners and it is a condition of accessing publications that users recognise and abide by the legal requirements associated with these

- Users may download and print one copy of any publication from the public portal for the purpose of private study or research.

- You may not further distribute the material or use it for any profit-making activity or commercial gain

If the publication is distributed under the terms of Article $25 \mathrm{fa}$ of the Dutch Copyright Act, indicated by the "Taverne" license above, 


\title{
Relevance of the Fear-Avoidance Model for Chronic Disability after Traumatic Brain Injury
}

\author{
Melloney L.M. Wijenberg, ${ }^{1,2}$ Amelia J. Hicks, ${ }^{3}$ Marina G. Downing, ${ }^{3}$ \\ Caroline M. van Heugten, ${ }^{1,2,4}$ Sven Z. Stapert, ${ }^{1,5}$ and Jennie L. Ponsford ${ }^{3}$
}

\begin{abstract}
Previous studies convincingly suggest that the biopsychosocial fear-avoidance model (FAM) may be of added value in understanding chronic disability after traumatic brain injury (TBI). In this model, persistent symptoms occur as a result of catastrophizing and fear-avoidance regarding initial symptoms, leading to depression, reduced mental activity, and greater disability in daily functioning. This study examined the FAM in a large English-speaking TBI sample. A cross-sectional study was conducted in 117 individuals with complicated mild, moderate, or severe TBI at 1-5 years post-injury. Participants completed questionnaires assessing personal, injury-related, and psychological characteristics. Reliability, correlational, and regression analyses were performed. Main outcome measures of chronic disability were depression, disuse (e.g., fewer mental activities), and functional disability. The results revealed that all correlations suggested by the FAM were significant. Catastrophizing thoughts were positively associated with TBI-related symptoms and fearavoidance thoughts. Main outcome measures were positively associated with fear-avoidance thoughts and TBI-related symptoms. Further, variables in the FAM were of additive value to personal, injury-related, and psychological variables in understanding chronic disability after TBI. The separate regression analyses for depression, fewer mental activities, and disability revealed "fear-avoidance thoughts" as the only consistent variable. In conclusion, this study shows the association of the FAM with chronic disability after TBI, which has implications for assessment and future management of the FAM in TBI in English-speaking countries. Longitudinal studies are warranted to further investigate and refine the model.
\end{abstract}

Keywords: chronic disability; chronic phase; fear-avoidance model; traumatic brain injury

\section{Introduction}

$\mathbf{T}$ RAUMATIC BRAIN INJURY (TBI) poses a major global health issue because of its high prevalence and significant societal costs. ${ }^{1}$ Severity of TBI is commonly categorized as mild, moderate, or severe depending on duration of post-traumatic amnesia (PTA), loss of consciousness, or Glasgow Coma Scale (GCS) score. ${ }^{2}$ TBI is associated with significant functional, emotional, cognitive, and behavioral symptoms that impact daily functioning and reduce quality of life. ${ }^{3}$ However, the extent and duration of these symptoms vary across individuals, and their impact on chronic disability, such as impaired daily life functioning, is not fully explained by injury-related or personal variables only (e.g., injury severity parameters, time since injury, age, or education). ${ }^{4-11}$ Numerous studies have highlighted the potential contribution of psychosocial variables (e.g., personality, coping style, anxiety, and depression) to explain chronic disability. ${ }^{8-18}$ The contribution of all these variables suggests the need for a biopsychosocial approach to understandng chronic disability after TBI.

One potential biopsychosocial approach that may explain persistent symptoms is the fear-avoidance model (FAM). This model has been validated in various other patient populations with bodily distress syndromes including those with chronic pain, tinnitus, chronic fatigue, whiplash syndrome, and fibromyalgia, as well as in cancer survivors. ${ }^{19-24}$ These syndromes have in common that they start with symptoms that evolve into chronic symptomatology in only a subset of patients. The FAM states that individual psychological reactions to changes as a consequence of an injury can influence the development and course of symptoms and, eventually, the emotional adaptation to these changes. ${ }^{25}$ Applying this model to symptoms after TBI, the persistent symptoms (i.e., somatic, cognitive, and emotional changes) are interpreted as a sign

\footnotetext{
${ }^{1}$ Department of Neuropsychology and Psychopharmacology, Faculty of Psychology and Neuroscience, and ${ }^{4}$ Department of Psychiatry and Neuropsychology, School for Mental Health and Neuroscience, Maastricht University, Maastricht, the Netherlands.

${ }^{2}$ Limburg Brain Injury Centre, Maastricht, the Netherlands.

${ }^{3}$ Monash-Epworth Rehabilitation Research Centre, Turner Institute for Brain and Mental Health, School of Psychological Sciences, Monash University, Melbourne, Australia.

${ }^{5}$ Department of Clinical and Medical Psychology, Zuyderland Medical Centre, Sittard-Geleen, the Netherlands.
} 
of severe brain pathology over which one experiences little or no control. Such catastrophizing thoughts tend to result in fear and avoidance of mental activities, also labeled as cogniphobia, ${ }^{26,27}$ and subsequently decrease activity levels, resulting in progressive symptoms of depression, reduction in mental activities (disuse), and enhanced functional disability (e.g., decreased ability to perform daily life activities such as work or social activities). This could, in turn, increase the number and magnitude of symptoms, concluding their cyclic pattern. ${ }^{26,27}$ This adapted FAM is depicted in Figure 1. Please note that the FAM poses "depression"/"disuse"/ "disability" on the same level in the cycle, assuming that high levels of fear-avoidance would lead to high levels of depression, disuse, and disability, and that these outcomes of chronic disability would then fuel the symptoms concluding its cyclic pattern.

Preliminary studies have suggested that the FAM, or fearavoidance on its own, is associated with chronic disability after $\mathrm{TBI},{ }^{28,29}$ especially in mild TBI, where there can be a clear mismatch between the expected good recovery and the unexpected persistence of symptoms. A discrepancy that is still not understood, Wijenberg and coworkers ${ }^{29}$ conducted a small cross-sectional study in which they found the first evidence for the FAM in individuals with TBI of all severities $(n=48)$. Further, a prospective larger study by Silverberg and coworkers ${ }^{28}$ highlighted the importance of fear-avoidance in understanding chronic disability after mild TBI. Despite the promising results, these studies are limited by their use of self-report measurements that require validation in TBI samples, small sample size, or having examined only the influence of fear-avoidance rather than additional variables in the proposed biopsychosocial FAM (see Fig. 1).

Therefore, this large cross-sectional study has two aims: first, to examine the associations among the variables of the FAM (see Fig. 1) in a large cohort of individuals with complicated mild to severe TBI; and, second, to investigate whether elements of the FAM (TBI-related symptoms, catastrophizing thoughts, and fearavoidance thoughts) would make an independent contribution to depression, disuse, and functional disability after TBI over and above the contribution of known personal, injury-related, and other psychological variables (e.g., pre-injury psychological treatment). Based on recent studies, it was hypothesized that the associations would be consistent with the FAM (see Fig. 1; e.g., catastrophizing thoughts will be positively associated with TBI-related symptoms

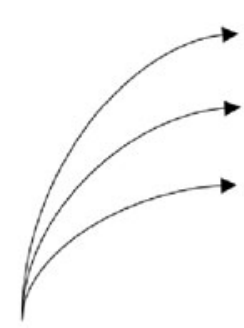

TBI-related fear-avoidance

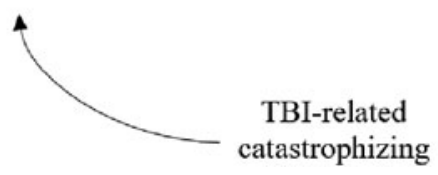

FIG. 1. Schematic overview of fear-avoidance model applied to TBI, permitted by Wijenberng, Stapert, Verbunt, Ponsford and van Heugten. ${ }^{29}$ TBI, Traumatic Brain Injury. and fear-avoidance thoughts, whereas depression, disuse, and functional disability will be positively associated with fear-avoidance thoughts and TBI-related symptoms). Further, we hypothesize that elements of the FAM (TBI-related symptoms, catastrophizing thoughts, and fear-avoidance thoughts) would make an independent contribution to chronic disability after TBI in terms of mood, disuse, and functional disability.

\section{Methods}

\section{Participants and procedures}

Participants were recruited at Monash Epworth Rehabilitation Research Centre (MERRC), Melbourne, Australia. Inclusion criteria were: (1) diagnosis of complicated mild to severe TBI, established by acute hospital evaluation; (2) date of injury between January 1, 2014 and January 1, 2018; and (3) being able to complete English online questionnaires (with assistance if needed). Individuals were invited to participate from December 2018 to March 2019, ensuring that data collection took place between 1 and 5 years post-injury.

Invitation letters were sent via e-mail or postal mail to eligible participants of an ongoing longitudinal cohort study, ${ }^{30,31}$ who had provided consent to be approached for other studies. If willing to participate, they provided informed consent and completed the questionnaires online (after entering their unique study identifier) or over the phone with author M.L.M.W. All procedures were approved by and in accordance with Epworth Healthcare and Monash University Human Research Ethics Committee (Project ID 16792). Participants did not receive any financial compensation for their participation.

\section{Measures}

Basic demographic information. Personal characteristics including gender, age, education years, marital status, and employment status were retrieved from the MERRC research database following informed consent. Medical data including time since injury, cause of injury, multi-trauma (e.g., comorbid orthopedic injuries), and severity of TBI were also retrieved from the research database. Indices for severity of injury were the GCS score and PTA duration, measured prospectively using the Westmead PTA Scale. ${ }^{32}$ Injury severity was based on PTA duration as follows: $<24$ h, mild; 24 h to 1 week, moderate; $>1$ week, severe. ${ }^{33}$ In cases of mild TBI, indications for complicated mild TBI (presence of abnormalities on computed tomography [CT]) were checked. Further, six yes/no-questions were asked at the beginning of the survey to assess pre-and post-injury neurological history, psychological treatment, and drug/alcohol abuse.

\section{The fear-avoidance model}

TBI-related symptoms. Symptoms and symptom severity were assessed with the Rivermead Post-Concussion Symptom Questionnaire (RPQ), developed by King and coworkers. ${ }^{34}$ This is a valid and reliable measure in individuals with mild to more severe TBI. ${ }^{35}$ It consists of 16 items, rated on a five-point Likert scale, measuring severity of symptoms in the past 24 hours in comparison with pre-injury levels. The total score ranges from 0 to 64 , with a higher score indicating a higher frequency and impact of symptoms. The presence of three or more remaining symptoms, indicated by at least three items with an item score of 2 or higher, was used as criterion for persistent disabling symptoms. ${ }^{29}$

Catastrophizing thoughts. Catastrophizing thoughts about TBI-related symptoms were assessed with the English version of the Post-Concussion Symptoms Catastrophizing Scale (PCS-CS). ${ }^{29}$ The PCS-CS has an excellent internal consistency and has been previously used in individuals with TBI. ${ }^{29}$ It consists of 13 items, 
rated on a five-point Likert scale, measuring the self-reported frequency of catastrophizing thoughts about an individual's selfreported symptoms on the RPQ. The score ranges from 0 and 52, with higher scores indicating a higher intensity of catastrophizing thoughts. The internal consistency of the PCS-CS in this study was excellent (Cronbach's $\alpha=0.97, n=116))^{36,37}$ The questionnaire is available on request. Although online administration is preferred for the PCS-CS (e.g. enabling tailored instructions to a person's answers on RPQ), see supplementary text for an overview of the questions.

Fear-avoidance thoughts. TBI-related fear-avoidance thoughts were assessed with the English version of the Fear of Mental Activity scale (FMA). ${ }^{29}$ The FMA has a good internal consistency and has been used in individuals with TBI before. ${ }^{29} \mathrm{It}$ includes 17 items, rated on a four-point Likert scale, measuring the self-reported frequency of fear-avoidance thoughts related to an individual's self-reported symptoms on the RPQ. In line with validation studies of the chronic pain fear-avoidance measure that the FMA is derived from, ${ }^{38-40}$ the four reversed items were not used in the scoring, resulting in 13 items. The score ranges from 13 to 52. The internal consistency of the 13-item FMA in this study was excellent (Cronbach's $\alpha=0.93, n=113$ ). ${ }^{36,37}$ The questionnaire is available on request. Although online administration is preferred for the FMA (e.g., enabling tailored instructions to a person's answers on RPQ), see supplementary text for an overview of the questions.

Depressive symptoms. Depressive symptoms were assessed with the depression subscale of the Hospital Anxiety and Depression Scale (HADS) ${ }^{41}$ It is a valid and reliable measure in individuals with TBI. ${ }^{42}$ It consists of seven items rated on a four-point Likert Scale with the total score ranging from 0 to 21 . A higher score indicates greater severity, with a score higher than 7 indicating clinically significant symptoms. ${ }^{42}$

Disuse. Validated questionnaires to assess "disuse of the brain"' are lacking. We translated disuse in the TBI-related FAM to "amount of mental activity." Therefore, disuse was assessed with one question: "How many hours a day do you currently spend performing mental activities such as writing, working on the computer, reading, and participating in a meeting?" In this study, "amount of mental activity" represents the inverse of "disuse," indicated by number of hours spent on mental activity per day. In other words, the scores were reversed to represent "disuse."

Disability. Functional disability was assessed with the selfreport version of the Glasgow Outcome Scale - Extended (GOS-E), developed by Wilson and coworkers. ${ }^{43}$ The original GOS-E, administered as an interview and developed by Jennett and coworkers, ${ }^{44}$ and the original GOS are the most widely used and accepted instruments in neurotrauma research for assessing outcomes after TBI. ${ }^{45}$ The postal version of the GOS-E is also found to be reliable to assess global outcome or disability. ${ }^{43}$ Based on a structured scoring system, the score ranges from 1 to 8 , with a higher score indicating a better global outcome. A score $\leq 6$ was used as indication of functional disability. ${ }^{17}$

\section{Statistical analysis}

Data analyses were performed using SPSS Statistics 24.0 for windows (IBM Corp., Armonk, NY). Missing data were not imputed, and were treated as missing in all analyses. Distributions of all variables were evaluated in terms of mean, standard deviation (SD), median, range, skewness, and kurtosis. Outliers and assumptions were checked. In case of non-normality (skewness or kurtosis values not between -1 and 1), non-parametric statistics were used. Sample characteristics are described by descriptive statistics. Participants were compared with non-responders on basic demographic information using Mann-Whitney $U$ tests for nonnormal distributed continuous variables, independent sample $t$ tests for normal distributed continuous variables, and Pearson $\chi^{2}$ tests for categorical variables. For all statistical tests, unless stated otherwise, an $\alpha$ level of 0.05 was used.

To test the relationships within the FAM (see Fig. 1), the correlations of the FAM were calculated by Spearman correlations (in case of non-normality and/or ordinal variables).

To explore whether the FAM explains depression, disuse, and functional disability independently after controlling for known variables, the interrelationships of depression, disuse, and functional disability with personal, injury-related, psychological characteristics, and the additional FAM variables were examined. Personal characteristics included age, gender, education years, employment status, marital status, and assessment method (online/ over the phone). Injury-related characteristics included GCS score, PTA duration, time since injury, cause of injury, multi-trauma, and neurological history (pre- and post-injury). Psychological characteristics included psychological treatment (pre- and post-injury) and drug/alcohol abuse (pre- and post-injury). The FAM variables included TBI-related symptoms, catastrophizing thoughts, and fear-avoidance thoughts.

For the interval variables, depression and disuse, backward multiple regression analyses were performed. Dummy variables were created for categorical variables (gender, employment status, marital status, assessment method, cause of injury, multitrauma, pre- and post-injury neurological history, psychological treatment, and drugs/alcohol abuse). The continuous variables (age, education in years, GCS score, PTA duration, time since injury, TBI-related symptoms, catastrophizing thoughts, fearavoidance thoughts) were centered (subtracting the median in case of non-normality or the mean in case of normality) and their quadratic terms were added. To prevent type 2 errors, the least significant variable was removed stepwise with a threshold of $\alpha=0.10$. In this process, dummy variables were treated as a block. Outliers (using box plots, studentized residuals, and centered leverage values) and influential cases (using Cook's distance) were checked, and if influential, removed as case. Collinearity and the homogeneity of residual variance were also checked for the full and final models.

For the ordinal variable, functional disability, the GOS-E was recoded into two groups: "Good Recovery" and "Poor Recovery." The outcomes "upper good" and "lower good" recovery were merged to create "Good Recovery," whereas the outcomes "upper moderate disability" - "vegetative state" denoted "Poor Recovery," resulting in a binary split used in other studies such as that of Ponsford and coworkers. ${ }^{17}$ Because of the limited sample size and the skewed distribution of many independent variables, binomial hierarchical logistical regression analysis was performed with the variables significantly related to GOS-E in the bivariate analyses. Mann-Whitney $U$ tests (continuous variables) and Pearson $\chi^{2}$ analysis (categorical variables) were used to compare performances of those in the "Good Recovery" with those in the "Poor Recovery" group according to personal, injury-related, and psychological characteristics, and the additional FAM variables. Only measures that were significantly related to GOS-E in the bivariate analyses were entered into the binomial hierarchical logistical regression. This regression was conducted to establish (1) whether the included FAM variables would improve the fit compared with included personal, injury-related, and other psychological characteristics; and (2) how well this model differentiated the "Good Recovery" from the "Poor Recovery" group. Bonferroni corrections for multiple comparisons were applied separately for each set of statistical tests. ${ }^{46}$ This strategy resulted in significance levels of $p=0.0125$ for the bivariate comparisons of continuous personal 
and injury-related variables with outcome; 0.0038 for the categorical personal and injury-related variables; 0.0167 for the bivariate comparisons of the addition FAM variables; and 0.0050 for the logistical regressions. Assumption of linearity of the continuous variables with respect to the logit of the dependent variable was assessed via the Box-Tidwell procedure. ${ }^{47}$ Further, the receiver operating characteristic (ROC) curve was inspected to reveal the discriminative value of the final model.

\section{Results}

\section{Participants}

Of the 191 individuals approached, 64 did not agree to participate and 10 were not reached, resulting in 117 participants $(61.3 \%)$. In total, 43 participants requested a phone interview to complete the questionnaires $(36.8 \%)$, and four stopped during the assessment (3.4\%). Two participants did not enter their unique study identifier when completing the questionnaires online, resulting in an anonymous response and preventing appropriate extraction of demographic information from the MERRC research database.

The final sample included 74 men and 41 women with a mean age of 51.63 years $(\mathrm{SD}=18.75 ;$ [18-87]). In most cases, TBI was caused by traffic accidents $(84.3 \%)$. Based on PTA duration, injury severity was considered mild for $13.5 \%$ (PTA $<24 \mathrm{~h}$ ), moderate for $17.3 \%$ (PTA $=1-7$ days), and severe for $69.2 \%$ (PTA $>7$ days). The mild group consisted solely of individuals with complicated mild TBI (presence of abnormalities on CT). Regarding work status, $63.7 \%$ were employed before the injury and $29.2 \%$ reported being able to work at the same level without problems after the injury. See Table 1 for an overview of all participants' characteristics. Sample size deviations are the results of missing data in the
MERRC research database or items missed by participants during online administration. Participants were older $(\Delta \mathrm{M}=17.02$ years; $U=2146.50$; standard error $[\mathrm{SE}]=373.84 ; p<0.01)$ and more often married $\left(\chi^{2}[5]=25.28 ; p<0.01\right)$ than non-responders. No group differences were found for any other personal characteristics (gender, education years, and employment status) or medical data (time since injury, cause of injury, multi-trauma, GCS score, and PTA duration).

\section{Relationships within the FAM}

See Table 2 for an overview of the scores on elements of the FAM and their percentage of participants with an impairment as defined by available cutoff scores (see Methods section). Spearman correlation analyses revealed that all correlations suggested by the FAM were significant $(p<0.05)$. See Figure 2 for a graphical presentation of the correlations within the FAM. Catastrophizing thoughts were positively associated with TBI-related symptoms $(r=0.80)$ and fear-avoidance thoughts $(r=0.70)$. Although all outcome measures (depression, disuse, and disability) were positively associated with fear-avoidance thoughts and TBI-related symptoms, the strongest association was seen between depression and TBI-related symptoms $(r=0.80)$.

\section{Explanation of depression}

Eight outliers were identified according to centered leverage values, and were removed for the final model. The final model revealed that TBI-related symptoms, fear-avoidance thoughts, and post-injury neurological history were significantly associated with depression $(F[3,99]=59.79, p<0.01)$, accounting for $64.4 \%$ of

Table 1. Descriptives of Participants

\begin{tabular}{|c|c|c|c|}
\hline & $\mathrm{n}$ & Value $^{\mathrm{a}}$ & $\%$ \\
\hline \multicolumn{4}{|l|}{ Personal characteristics } \\
\hline Age (years) & 115 & 52 (34) [18-87] & \\
\hline Gender & 115 & & $64.3 \%$ male \\
\hline Education years & 105 & $11.97(2.39)[8-18]$ & \\
\hline Employment status pre-injury & 115 & & $\begin{array}{l}49.6 \% \text { full-time employed } \\
4.3 \% \text { part-time employed }\end{array}$ \\
\hline Working status: pre-injury (GOS-E) & 113 & & $63.7 \%$ employed \\
\hline Working status: current (GOS-E) & 113 & & $\begin{array}{l}29.2 \% \text { same work without problems } \\
23.0 \% \text { unable to work because ofTBI }\end{array}$ \\
\hline Marital status & 113 & & $50.4 \%$ married or de facto \\
\hline Assessment method & 115 & & $\begin{array}{l}62.6 \% \text { online } \\
37.4 \% \text { guided over the phone }\end{array}$ \\
\hline \multicolumn{4}{|l|}{ Injury-related characteristics } \\
\hline GCS score & 105 & $12(8)[3-15]$ & \\
\hline PTA duration (days) & 104 & 15 (19) [0-180] & \\
\hline Time since injury (years) & 115 & $2.65(1.16)[1-5]$ & \\
\hline Cause of injury & 115 & & $84.3 \%$ traffic accident \\
\hline Multi-trauma & 115 & & $80.0 \%$ multi-trauma \\
\hline Neurological history pre-injury & 117 & & $3.4 \%$ yes \\
\hline Neurological history post-injury & 117 & & $30.2 \%$ yes \\
\hline \multicolumn{4}{|l|}{ Psychological characteristics } \\
\hline Psychological treatment pre-injury & 117 & & $26.5 \%$ yes \\
\hline Psychological treatment post-injury & 117 & & $53.8 \%$ yes \\
\hline Drugs/alcohol abuse pre-injury & 117 & & $9.4 \%$ yes \\
\hline Drugs/alcohol abuse post-injury & 117 & & $4.3 \%$ yes \\
\hline
\end{tabular}

${ }^{a}$ Depending on normality, mean (standard deviation) [range] or median (interquartile range) [range] are reported.

GOS-E, Glasgow Outcome Scale - Extended; GCS, Glasgow Coma Scale; PTA, post-traumatic amnesia. 
Table 2. Descriptives of the Fear-Avoidance Model

\begin{tabular}{lccc}
\hline & $\mathrm{n}$ & Value $^{\mathrm{a}}$ & $\% I$ \\
\hline $\begin{array}{l}\text { TBI-related symptoms (RPQ) } \\
\text { Catastrophizing thoughts }\end{array}$ & 115 & $24(23)[0-54]$ & 80.0 \\
$\quad($ PCS-CS) & 116 & $12.27(13.07)[0-52]$ & - \\
$\begin{array}{l}\text { Fear-avoidance thoughts } \\
\quad(\text { FMA) }\end{array}$ & 113 & $25.19(8.33)[13-44]$ & - \\
$\begin{array}{l}\text { Depression (HADS D) } \\
\text { Disuse (amount of mental } \\
\quad \text { activity) }\end{array}$ & 113 & $6.12(4.68)[0-18]$ & 36.3 \\
$\begin{array}{l}\text { Disability (GOS-E) } \\
\text { (G) }\end{array}$ & 113 & $6.26(3.11)[0-15]$ & - \\
\hline
\end{tabular}

${ }^{\mathrm{a}}$ For continuous variables depending on normality, mean (standard deviation) [range] or median (interquartile range) [range] are reported.

$\% \mathrm{I}$, percentage of participants with an impairment as defined by the cutoff scores (see Methods section); RPQ, Rivermead Post-Concussion Symptom Questionnaire; PCS-CS, Post-Concussion Symptoms Catastrophizing Scale; FMA, Fear of Mental Activity scale; HADS D, Depression subscale of the Hospital Anxiety and Depression Scale; GOS-E, Glasgow Outcome Scale - Extended.

the variation in depression (see Table 3). The results show that participants who reported more TBI-related symptoms, fearavoidance thoughts, or no other neurological disease post-injury reported more depressive symptoms.

\section{Explanation of disuse}

One outlier on disuse was identified and removed for the final model. The final model revealed that fear-avoidance thoughts and years of education were associated with disuse $(F[2,96]=13.73$, $p<0.01$ ), accounting for $22.2 \%$ of the variation in disuse (see Table 3). The results show that participants who reported more fear-avoidance thoughts or had completed fewer education years reported having spent less time on mental activities.

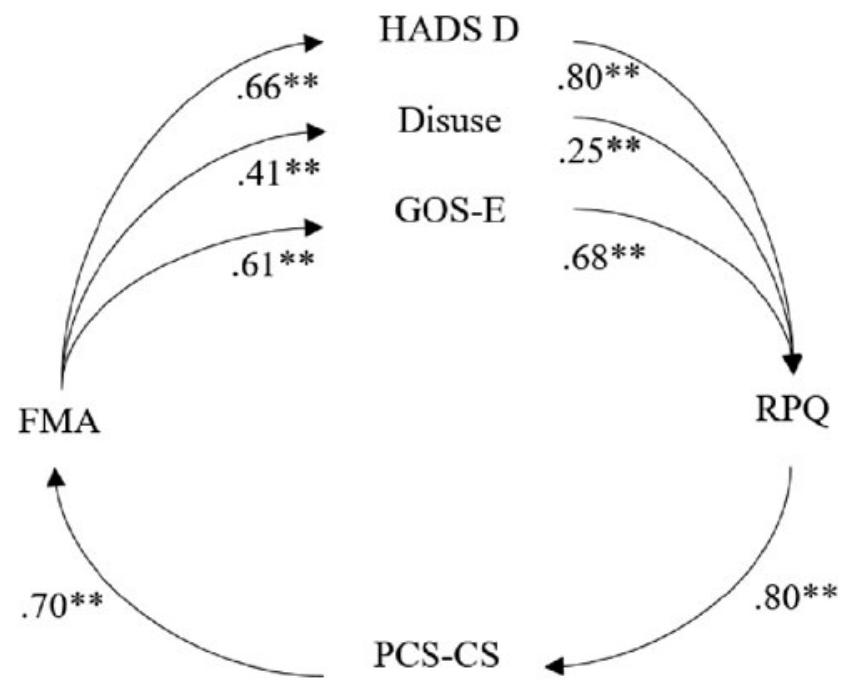

FIG. 2. Spearman correlations of the fear-avoidance model in the current sample. Values shown are based on cross-sectional data. $* p<0.05, * * p<0.01$. HADS D, Depression subscale of the Hospital Anxiety and Depression Scale; GOS-E, Glasgow Outcome Scale - Extended; FMA, Fear of Mental Activity scale; RPQ, Rivermead Post-Concussion Symptom Questionnaire; PCSCS, Post-Concussion Symptoms Catastrophizing Scale.

\section{Explanation of functional disability}

Bivariate analyses revealed that only age, post-injury neurological history, TBI-related symptoms, catastrophizing thoughts, and fear-avoidance thoughts were significantly related to functional disability. Age was significantly higher in the "Good Recovery" group $(\Delta$ Mean $\operatorname{Rank}=15.47 ; U=1942.50 ; \mathrm{SE}=168.34 ; p=0.01$; $\left.\chi^{2}[5]=25.28 ; p<0.01\right)$, whereas pre-injury neurological history was significantly less prevalent in the "Good Recovery" group $\left(\chi^{2}[1]=12.43 ; p<0.01\right)$. Specifically for the FAM-related variables, the "Good Recovery" group was significantly associated with lower levels of TBI-related symptoms ( $\Delta$ Mean Rank $=$ 36.45; $U=541.00 ; \mathrm{SE}=170.78 ; p<0.01)$, catastrophizing thoughts $(\Delta$ Mean Rank $=33.90 ; U=630.00 ; \mathrm{SE}=172.17 ; p<0.01)$, and fear-avoidance thoughts $(\Delta$ Mean Rank $=33.31 ; U=646.50 ; \mathrm{SE}=$ $172.69 ; p<0.01)$. A binomial logistical hierarchical regression was performed to ascertain the association of age, post-injury neurological history, catastrophizing, fear-avoidance, and TBI-related symptoms with the likelihood that participants reported good recovery. Based on this assessment, there were two outliers identified, and all assumptions, including no multicollinearity, were met. At the first step (age + post-injury neurological history), the logistical regression model was statistically significant $\left(\chi^{2}[2]=\right.$ $14.68, p<0.01$ ). At the second step (+ FAM-related variables) the logistical regression model was statistically significant as well $\left(\chi^{2}[5]=50.53, p<0.01\right)$ and significantly improved compared with the previous step $\left(\chi^{2}[3]=35.85, p<0.01\right)$ (see Table 4$)$. The final model explained $49.7 \%$ (Nagelkerke $R^{2}$ ) of the variance in functional disability and correctly classified $78.9 \%$ of cases. Sensitivity was $79.2 \%$ and specificity was $78.7 \%$. Of the five independent variables, none were statistically significant $(p>0.05)$. The area under the ROC curve was 0.87 (95\% confidence interval [CI], 0.798-0.931), which is an excellent level of discrimination according to Hosmer et and coworkers. ${ }^{48}$

\section{Discussion}

The current study examined the FAM in a large Englishspeaking TBI sample. The first aim was to determine whether the relationships among the FAM variables were found in a large cohort of individuals with complicated mild to severe TBI. In line with the findings of Wijenberg and coworkers, ${ }^{29}$ all correlations suggested by the FAM were significant. We found similar or even greater correlations in the current study, thereby replicating the previous findings in a large English-speaking Australian cohort. The results further support the presence of these relationships in individuals with moderate to severe TBI as well as in mild TBI, which has been the focus of most previous studies examining this construct.

The second aim was to investigate whether the FAM explains chronic disability after TBI over and above known personal, injuryrelated, and other psychological variables. In line with Silverberg and coworkers, ${ }^{28}$ we found that the variables in the FAM are of additive value to personal, injury-related, and other psychological variables in understanding unfavorable chronic disability after TBI in terms of depression, disuse, and disability. The separate analyses for our three outcome measures (depression, disuse, and disability) revealed "fear-avoidance thoughts" to be the only consistent significant variable across the analyses. Higher levels of fearavoidance thoughts were associated with higher levels of depression, less mental activity, and more functional disability over and above other known variables. This shows that how people think about their symptoms is related to chronic disability after TBI and may 
Table 3. Final Regression Model for the Outcomes Depression and Disuse

\begin{tabular}{|c|c|c|c|c|c|c|c|c|}
\hline \multirow[b]{2}{*}{ Predictor } & \multicolumn{4}{|c|}{ Depression $(\mathrm{n}=103)^{\mathrm{a}}$} & \multicolumn{4}{|c|}{ Disuse $(\mathrm{n}=99)^{\mathrm{b}}$} \\
\hline & $B$ & $\beta$ & $S E$ of $B$ & $\mathrm{p}$ & $B$ & $\beta$ & $S E$ of $B$ & $\mathrm{p}$ \\
\hline Constant & 5.69 & & 0.31 & $<0.01$ & 4.20 & & 0.27 & $<0.01$ \\
\hline Fear-avoidance thoughts & 0.11 & 0.21 & 0.05 & 0.02 & -0.10 & -0.28 & 0.03 & $<0.01$ \\
\hline TBI-related symptoms & 0.21 & 0.70 & 0.03 & $<0.01$ & & & & \\
\hline Neurological history post-injury & 0.83 & 0.16 & 0.35 & 0.02 & & & & \\
\hline Education years & & & & & 0.39 & 0.32 & 0.12 & $<0.01$ \\
\hline
\end{tabular}

${ }^{\mathrm{a}}$ Depression; scale range $=[0.00 ; 18.00], R^{2}=0.64, \mathrm{MSE}=7.61$. The prediction equation was "depression $=5.69+0.21 \times \mathrm{TBI}$-related symptoms $(\mathrm{RPQ}-$ $24)+0.11 \times$ fear-avoidance thoughts (FMA- 25.19$)+0.83 \times$ post-injury neurological history $(-1=$ yes; $+1=$ no)."

${ }^{b}$ Disuse; scale range $=[0.00 ; 12.00], R^{2}=0.22, \mathrm{MSE}=7.12$. The prediction equation was "hours performing mental activities $=4.20+0.39 \times \mathrm{education}$ years (education years -11.97$)+-0.10 \times$ fear-avoidance thoughts (FMA-25.19)."

TBI, traumatic brain injury; MSE, mean squared error; RPQ, score on Rivermead Post-Concussion Symptom Questionnaire; FMA, score on Fear of Mental Activity Scale.

suggest further investigation of fear-avoidance as potential treatment target. Other significant contributors in the final models of depression, disuse, and functional disability included other FAM variables (TBI-related symptoms, catastrophizing thoughts), injuryrelated characteristics (post-injury neurological history), and personal characteristics (education years, age). Looking specifically at one of the most common measures for outcome after TBI, functional disability measured by the GOS-E, results reveal that the FAM-related variables were associated with functional disability over and above personal and injury-related variables, and that together with age and post-injury neurological history, these have a good level of discrimination. These results are also in line with multiple studies addressing the need for a biopsychosocial approach to understanding chronic disability after TBI. ${ }^{8-14}$

Nevertheless, several findings were not consistent with our expectations. Although the regression analyses of disability revealed that the final model significantly explained disability, explaining $49.7 \%$ (Nagelkerke $R^{2}$ ) of the variance and correctly classifying $78.9 \%$ of cases, none of the five independent variables in the model were significant. This could be a result of correlations among covariates in the model, lower power caused by fewer observations, or selection bias introduced by missing values on other covariates. Although our analyses met the assumption of at least 15 cases per independent variable, cross-validation should be performed to further validate our results. Further, we found that the occurrence of another neurological injury after TBI (e.g., another TBI or stroke) resulted in fewer depressive symptoms. A plausible explanation for this unexpected finding may be found in the phrasing of the ques- tion. Participants were asked by means of one "yes/no" question if, since the injury, they had been affected or currently felt affected by a new neurological disorder. Unfortunately, in retrospect, this phrasing could be misunderstood as meaning experiencing impact of their TBI, limiting the reliability of the answer given.

There are several limitations to consider in the current study, resulting in suggestions for future research. First, the results should be interpreted with caution because of the cross-sectional nature of the study. As the FAM describes a process over time, no conclusions can be drawn regarding mediation or causation. Therefore, a large longitudinal study assessing the FAM and its influence on chronic disability over time is warranted. Second, because of the lack of a validated questionnaire, disuse was measured by one nonvalidated question. Further, the Dutch version of the PCS-CS and FMA were validated, but future studies are needed for (further) validation and reference data of the English PCS-CS, FMA, and measure for disuse. Although less specific for mental activities, future studies could also use alternative measures for disuse that have been used and validated before in neurological patient populations, such as the Cognitive Reserve Index Questionnaire ${ }^{49}$ or a measure assessing limiting behavior. ${ }^{50,51}$ Moreover, recently, a new questionnaire to assess fear-avoidance behavior after traumatic brain injury (FAB-TBI) has been developed, which was derived through principal component analysis of existing fearavoidance measures and was found to be a psychometrically sound measure by applying Rasch analysis. ${ }^{28,52}$ The FAB-TBI and FMA are both short self-report questionnaires derived from existing measures from the chronic pain literature. However, they differ in

Table 4. Logistical Regression Predicting Likelihood of Good Recovery Based on Age, Post-Injury Neurological Injury, and FAM-Related Variables

\begin{tabular}{|c|c|c|c|c|c|c|c|c|}
\hline \multirow[b]{3}{*}{ Predictor } & \multicolumn{8}{|c|}{ Disability $(\mathrm{n}=109)$} \\
\hline & \multirow[b]{2}{*}{$B$} & \multirow[b]{2}{*}{$S E$} & \multirow[b]{2}{*}{ Wald } & \multirow[b]{2}{*}{ df } & \multirow[b]{2}{*}{$\mathrm{p}$} & \multirow[b]{2}{*}{ Odds ratio } & \multicolumn{2}{|c|}{$95 \%$ CI for odds ratio } \\
\hline & & & & & & & Lower & Upper \\
\hline Constant & 4.46 & 1.42 & 9.90 & 1 & $<0.01$ & 86.76 & & \\
\hline Age & -0.02 & 0.02 & 1.42 & 1 & 0.23 & 0.98 & 0.95 & 1.01 \\
\hline Post-injury neurological history & -1.31 & 0.73 & 3.19 & 1 & 0.07 & 0.27 & 0.07 & 1.14 \\
\hline TBI-related symptoms & -0.05 & 0.03 & 2.21 & 1 & 0.14 & 0.96 & 0.90 & 1.02 \\
\hline Catastrophizing thoughts & -0.05 & 0.04 & 1.74 & 1 & 0.19 & 0.95 & 0.88 & 1.03 \\
\hline Fear-avoidance thoughts & -0.08 & 0.05 & 3.18 & 1 & 0.07 & 0.92 & 0.84 & 1.01 \\
\hline
\end{tabular}

FAM, Fear-Avoidance Model; SE, standard error; CI, confidence interval. Disability is defined as " $1=$ good recovery" or " $0=$ poor recovery" based on a binary split of the Glasgow Outcome Scale - Extended. Post-injury neurological history is coded as " $1=$ neurological history" and " $0=$ no history." 
that the FAB-TBI is, in contrast to the FMA, limited by no tailored administration and signs of multi-dimensionality, but the validation process of the FAB-TBI is further advanced. Future studies should incorporate both the FAB-TBI and FMA to further validate these measures and compare strengths and weaknesses for implications regarding their use. Third, although many variables were taken into account, several variables, such as personal characteristics (e.g. coping, personality, disease expectancies, and impaired awareness) and environmental characteristics (such as content and amount of, and satisfaction with, professional and personal support), known to impact chronic disability after TBI, ${ }^{53}$ were not assessed. Future research should incorporate these variables as well to demonstrate the contribution of the FAM to chronic disability after TBI. Lastly, questionnaires were administered online or over the phone. Selection bias could have occurred as a consequence of online administration, which may be too difficult for some individuals with TBI. However, online administration was purposely selected because it enabled individuals with TBI to complete the questionnaires at their own pace and allowed for recruitment of rural and remote participants. Further, for those who required extra assistance, administration over the phone was also offered.

Despite some unexpected findings and limitations, this is the first large study examining the associations of the variables in the FAM with chronic disability after complicated mild to severe TBI. Although longitudinal studies are warranted, the findings favor the assessment of the FAM in English-speaking countries and may suggest further investigation of fear-avoidance as a potential treatment target. The FAM provides the theoretical underpinnings of a well-established treatment; namely exposure in vivo therapy. ${ }^{54}$

\section{Acknowledgments}

We thank all participants for their participation in this study. Further, we thank Lisa Johnston, David Lawson and Olivia McConchie for their help with the data collection.

\section{Funding Information}

No funding was received.

\section{Author Disclosure Statement}

No competing financial interests exist.

\section{Supplementary Material}

Supplementary Text

\section{References}

1. Corrigan, J.D., Selassie, A.W., and Orman, J.A.L. (2010). The epidemiology of traumatic brain injury. J. Head Trauma Rehabil. 25, 72-80.

2. Levin, H.S., and Diaz-Arrastia, R.R. (2015). Diagnosis, prognosis, and clinical management of mild traumatic brain injury. Lancet Neurol. 14, 506-517.

3. Greenwald, B.D., and Rigg, J.L. (2009). Neurorehabilitation in traumatic brain injury: does it make a difference? Mt. Sinai J. Med. 76, $182-189$.

4. Rassovsky, Y., Levi, Y., Agranov, E., Sela-Kaufman, M., Sverdlik, A., and Vakil, E. (2015). Predicting long-term outcome following traumatic brain injury (TBI). J. Clin. Exp. Neuropsychol. 37, 354-366.

5. Novack, T.A., Bush, B.A., Meythaler, J.M., and Canupp, K. (2001). Outcome after traumatic brain injury: pathway analysis of contributions from premorbid, injury severity, and recovery variables. Arch. Phys. Med. Rehabil. 82, 300-305.
6. Cuthbert, J.P., Corrigan, J.D., Harrison-Felix, C., Coronado, V., Dijkers, M.P., Heinemann, A.W., and Whiteneck, G.G. (2011). Factors that predict acute hospitalization discharge disposition for adults with moderate to severe traumatic brain injury. Arch. Phys. Med. Rehabil. 92, 721-730.

7. Ruff, R. (2005). Two decades of advances in understanding of mild traumatic brain injury. J. Head Trauma Rehabil. 20, 5-18.

8. Scheenen, M.E., Spikman, J.M., de Koning, M.E., van der Horn, H.J., Roks, G., Hageman, G., and van der Naalt, J. (2016). Patients "at risk" of suffering from persistent complaints after mild traumatic brain injury: the role of coping, mood disorders and post-traumatic stress. J. Neurotrauma. 34, 31-37.

9. Silverberg, N.D., Gardner, A.J., Brubacher, J.R., Panenka, W.J., Li, J.J., and Iverson, G.L. (2015). Systematic review of multivariable prognostic models for mild traumatic brain injury. J. Neurotrauma 32, 517-526.

10. Theadom, A., Parag, V., Dowell, T., McPherson, K., Starkey, N., Barker-Collo, S., Jones, K., Ameratunga, S., and Feigin, V.L. (2016). Persistent problems 1 year after mild traumatic brain injury: a longitudinal population study in New Zealand. Br. J. Gene. Pract. 66, e16-23.

11. Wäljas, M., Iverson, G.L., Lange, R.T., Hakulinen, U., Dastidar, P., Huhtala, H., Liimatainen, S., Hartikainen, K., and Öhman, J. (2015). A prospective biopsychosocial study of the persistent post-concussion symptoms following mild traumatic brain injury. J. Neurotrauma 32 , 534-547.

12. Ponsford, J. (2017). Anxiety and depression following TBI, in: Neurobehavioural disability and social handicap following traumatic brain injury. T.M. McMillan, R.L. Wood (eds.). Routledge: Milton Park, Abingdon, Oxon; New York, NY, pps. 167-177.

13. Ponsford, J., Wong, D., McKay, A., Alway, Y., Haines, K., Lee, N.K., Downing, M. and O'Donnell, M.L. (2016). Depression and anxiety following traumatic brain injury: Can these high prevalence disorders be effectively treated using adapted cognitive behavioural therapy? In: Innovations and Future Directions in the Behavioural and Cognitive Therapies. R.G. Menzies, M. Kyrios, and N. Kazantzis, (eds.). Australian Academic Press: Samford Valley, QLD, pps. 182-186.

14. Wardlaw, C., Hicks, A.J., Sherer, M., and Ponsford, J.L. (2018). Psychological resilience is associated with participation outcomes following mild to severe traumatic brain injury. Front Neurol. 9, 563.

15. Belanger, H.G., Kretzmer, T., Vanderploeg, R.D., and French, L.M (2010). Symptom complaints following combat-related traumatic brain injury: relationship to traumatic brain injury severity and posttraumatic stress disorder. J. Int. Neuropsychol. Soc. 16, 194-199.

16. Dikmen, S., Machamer, J., Fann, J.R., and Temkin, N.R. (2010). Rates of symptom reporting following traumatic brain injury. J. Int. Neuropsychol. Soc. 16, 401-411.

17. Ponsford, J., Draper, K. and Schönberger, M. (2008). Functional outcome 10 years after traumatic brain injury: its relationship with demographic, injury severity, and cognitive and emotional status. J. Int. Neuropsychol. Soc. 14, 233-242.

18. van der Horn, H.J., Spikman, J.M., Jacobs, B., and van der Naalt, J. (2013). Postconcussive complaints, anxiety, and depression related to vocational outcome in minor to severe traumatic brain injury. Arch. Phys. Med. Rehabil. 94, 867-874.

19. Vlaeyen, J.W., and Linton, S.J. (2012). Fear-avoidance model of chronic musculoskeletal pain: 12 years on. Pain 153, 1144-1147.

20. Cima, R.F., Crombez, G., and Vlaeyen, J.W. (2011). Catastrophizing and fear of tinnitus predict quality of life in patients with chronic tinnitus. Ear Hear. 32, 634-641.

21. Nijs, J., Roussel, N., Van Oosterwijck, J., De Kooning, M., Ickmans, K., Struyf, F., Meeus, M., and Lundberg, M. (2013). Fear of movement and avoidance behaviour toward physical activity in chronicfatigue syndrome and fibromyalgia: state of the art and implications for clinical practice. Clin. Rheumatol. 32, 1121-1129.

22. Wijenberg, M.L., Stapert, S.Z., Köhler, S., and Bol, Y. (2016) Explaining fatigue in multiple sclerosis: cross-validation of a biopsychosocial model. J. Behav. Med. 39, 815-822.

23. Nieto, R., Miró, J., and Huguet, A. (2009). The fear-avoidance model in whiplash injuries. Eur. J. Pain. 13, 518-523.

24. Velthuis, M.J., Peeters, P.H., Gijsen, B.C., van den Berg, J.-P., Koppejan-Rensenbrink, R.A., Vlaeyen, J.W., and May, A.M. (2012). Role of fear of movement in cancer survivors participating in a rehabilitation program: a longitudinal cohort study. Arch. Phys. Med. Rehabil. 93, 332-338. 
25. Vlaeyen, J.W., Crombez, G., and Linton, S.J. (2016). The fearavoidance model of pain. Pain 157, 1588-1589.

26. Martelli, M., MacMillan, P., and Grayson, R. (1999). Kinesiophobia and cogniphobia: Avoidance-conditioned pain-related disability (ACPRD). Arch. Clin. Neuropsychol. 14, 804-804.

27. Todd, D., Martelli, M., and Grayson, R. (1998). The Cogniphobia Scale (C-Scale): a measure of headache impact. Test in the public domain.

28. Silverberg, N.D., Panenka, W., and Iverson, G.L. (2018). Fear avoidance and clinical outcomes from mild traumatic brain injury. J. Neurotrauma 35, 1864-1873.

29. Wijenberg, M.L., Stapert, S.Z., Verbunt, J.A., Ponsford, J.L., and van Heugten, C.M. (2017). Does the fear avoidance model explain persistent symptoms after traumatic brain injury? Brain Inj. 31, 15971604.

30. Ponsford, J.L., Downing, M.G., Olver, J., Ponsford, M., Acher, R., Carty, M., and Spitz, G. (2014). Longitudinal follow-up of patients with traumatic brain injury: outcome at two, five, and ten years postinjury. J. Neurotrauma 31, 64-77.

31. Ponsford, J.L., Olver, J., and Curran, C. (1995). A profile of outcome: 2 years after traumatic brain injury. Brain Inj. 9, 1-10.

32. Shores, E.A., Marosszeky, J.E., Sandanam, J., and Batchelor, J. (1986). Preliminary validation of a clinical scale for measuring the duration of post-traumatic amnesia. Med. J. Aust. 144, 569-572.

33. Draper, K., Ponsford, J., and Schönberger, M. (2007). Psychosocial and emotional outcomes 10 years following traumatic brain injury. J. Head Trauma Rehabil. 22, 278-287.

34. King, N.S., Crawford, S., Wenden, F.J., Moss, N.E.G., and Wade, D.T. (1995). The Rivermead Post Concussion Symptoms Questionnaire: a measure of symptoms commonly experienced after head injury and its reliability. J. Neurol. 242, 587-592.

35. Eyres, S., Carey, A., Gilworth, G., Neumann, V., and Tennant, A. (2005). Construct validity and reliability of the Rivermead postconcussion symptoms questionnaire. Clin. Rehabil. 19, 878-887.

36. Mallery, P., and George, D. (2003). SPSS for Windows Step by Step: A Simple Guide and Reference. Allyn, Bacon: Boston.

37. Kline, P. (2013). Handbook of Psychological Testing. London: Routledge.

38. Goubert, L., Crombez, G., Van Damme, S., Vlaeyen, J.W., Bijttebier, P., and Roelofs, J. (2004). Confirmatory factor analysis of the Tampa Scale for Kinesiophobia: invariant two-factor model across low back pain patients and fibromyalgia patients. Clin. J. Pain 20, 103-110.

39. Houben, R.M., Leeuw, M., Vlaeyen, J.W., Goubert, L., and Picavet, H.S. (2005). Fear of movement/injury in the general population: factor structure and psychometric properties of an adapted version of the Tampa Scale for Kinesiophobia. J. Behav. Med. 28, 415-424.

40. Roelofs, J., Goubert, L., Peters, M.L., Vlaeyen, J.W., and Crombez, G. (2004). The Tampa Scale for Kinesiophobia: further examination of psychometric properties in patients with chronic low back pain and fibromyalgia. Eur. J. Pain 8, 495-502.

41. Zigmond, A.S., and Snaith, R.P. (1983). The hospital anxiety and depression scale. Acta Psychiatr. Scand. 67, 361-370.

42. Whelan-Goodinson, R., Ponsford, J., and Schönberger, M. (2009). Validity of the Hospital Anxiety and Depression Scale to assess depression and anxiety following traumatic brain injury as compared with the Structured Clinical Interview for DSM-IV. J. Affect. Disord. 114, 94-102.

43. Wilson, J., Edwards, P., Fiddes, H., Stewart, E., and Teasdale, G. (2002). Reliability of postal questionnaires for the Glasgow Outcome Scale. J. Neurotrauma 19, 999-1005.

44. Jennett, B., Snoek, J., Bond, M., and Brooks, N. (1981). Disability after severe head injury: observations on the use of the Glasgow Outcome Scale. J. Neurol. Neurosurg. Psychiatry 44, 285-293.

45. Bullock, M.R., Merchant, R.E., Choi, S.C., Gilman, C.B., Kreutzer, J.S., Marmarou, A., and Teasdale, G.M. (2002). Outcome measures for clinical trials in neurotrauma. Neurosurg. Focus 13, 1-11.

46. Tabachnick, B.G., Fidell, L.S., and Ullman, J.B. (2007). Using Multivariate Statistics. Vol 5. Pearson: Boston.

47. Box, G.E., and Tidwell, P.W. (1962). Transformation of the independent variables. Technometrics 4, 531-550.

48. Hosmer, D.W., Lemeshow, S., and Sturdivant, R.X. (2013). Applied Logistic Regression, Vol 398. Hoboken, NJ: John Wiley \& Sons.

49. Nucci, M., Mapelli, D., and Mondini, S. (2012). Cognitive Reserve Index questionnaire (CRIq): a new instrument for measuring cognitive reserve. Aging Clin. Exp. Res. 24, 218-226.

50. Spence, M., Moss-Morris, R., and Chalder, T. (2005). The Behavioural Responses to Illness Questionnaire (BRIQ): a new predictive measure of medically unexplained symptoms following acute infection. Psychol. Med. 35, 583-593.

51. Greenberg, J., Mace, R.A., Funes, C.J., Silverberg, N.D., Iverson, G.L., Caplan, D.N., and Vranceanu, A.-M. (2020). Pain catastrophizing and limiting behavior mediate the association between anxiety and postconcussion symptoms. Psychosomatics 61, 49-55.

52. Snell, D.L., Siegert, R.J., Debert, C., Cairncross, M., and Silverberg, N.D. (2020). Evaluation of the fear avoidance behavior after traumatic brain injury questionnaire. J. Neurotrauma 37, 1566-1573.

53. Steiner, W.A., Ryser, L., Huber, E., Uebelhart, D., Aeschlimann, A., and Stucki, G. (2002). Use of the ICF model as a clinical problemsolving tool in physical therapy and rehabilitation medicine. Phys. Ther. 82, 1098-1107.

54. Woods, M.P., and Asmundson, G.J. (2008). Evaluating the efficacy of graded in vivo exposure for the treatment of fear in patients with chronic back pain: a randomized controlled clinical trial. Pain 136, 271-280.

Address correspondence to:

Jennie L. Ponsford, PhD

Monash Epworth Rehabilitation Research Centre

Turner Institute for Brain and Mental Health School of Psychological Sciences Monash University 18 Innovation Walk Clayton, Victoria 3800 Australia

E-mail: jennie.ponsford@monash.edu 